Erratum

\title{
Erratum to "Size of the Optic Nerve Head and Its Relationship with the Thickness of the Macular Ganglion Cell Complex and Peripapillary Retinal Nerve Fiber Layer in Patients with Primary Open Angle Glaucoma"
}

\author{
Nobuko Enomoto, Ayako Anraku, Kyoko Ishida, Asuka Takeyama, \\ Fumihiko Yagi, and Goji Tomita \\ Department of Ophthalmology, Toho University, Ohashi Medical Center, 2-17-5 Ohashi, Meguro-ku 153-8515, Japan \\ Correspondence should be addressed to Nobuko Enomoto; nobuko.enomoto@med.toho-u.ac.jp \\ Received 14 September 2015; Accepted 20 September 2015
}

Copyright (C) 2015 Nobuko Enomoto et al. This is an open access article distributed under the Creative Commons Attribution License, which permits unrestricted use, distribution, and reproduction in any medium, provided the original work is properly cited.

TABLE 5: Multiple regression analysis for the relationship between $\mathrm{MD}$ and other factors.

\begin{tabular}{lccccc}
\hline & Slope & SE & $\beta$ & $95 \%$ CI & $P$ value \\
\hline Age & 0.001 & 0.030 & 0.003 & $-0.058,0.060$ & 0.980 \\
Ref. & $<0.001$ & 0.148 & $<0.001$ & $-0.294,0.295$ & 0.997 \\
ONH area & 0.065 & 0.720 & 0.010 & $-1.368,1.498$ & 0.929 \\
Rim area & 1.415 & 1.150 & 0.145 & $-0.872,3.703$ & 0.222 \\
mGCC & 0.063 & 0.047 & 0.174 & $-0.029,0.156$ & 0.178 \\
thickness & & & & & \\
$\begin{array}{l}\text { cpRNFL } \\
\text { thickness }\end{array}$ & 0.075 & 0.044 & 0.221 & $-0.013,0.163$ & 0.094 \\
\hline
\end{tabular}

MD: mean deviation, SE: standard error, $\beta$ : standardized partial regression coefficient, CI: confidence interval, Ref.: refractive errors in the spherical equivalent, ONH: optic nerve head, mGCC: macular ganglion cell complex, and cpRNFL: circumpapillary retinal nerve fiber layer.

In the paper titled "Size of the Optic Nerve Head and Its Relationship with the Thickness of the Macular Ganglion Cell Complex and Peripapillary Retinal Nerve Fiber Layer in Patients with Primary Open Angle Glaucoma," [1] there was a typographical error in Table 5. The value of SE/age in Table 5 should be written as 0.030 . Corrected Table 5 is shown.

This correction does not change any conclusion or findings of the paper.

\section{References}

[1] N. Enomoto, A. Anraku, K. Ishida, A. Takeyama, F. Yagi, and G. Tomita, "Size of the optic nerve head and its relationship with the thickness of the macular ganglion cell complex and peripapillary retinal nerve fiber layer in patients with primary open angle glaucoma," Journal of Ophthalmology, vol. 2015, Article ID 186249, 6 pages, 2015. 


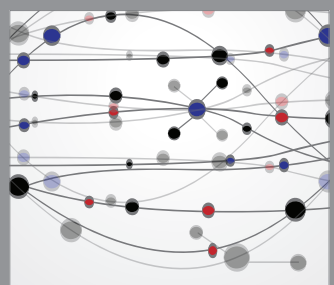

The Scientific World Journal
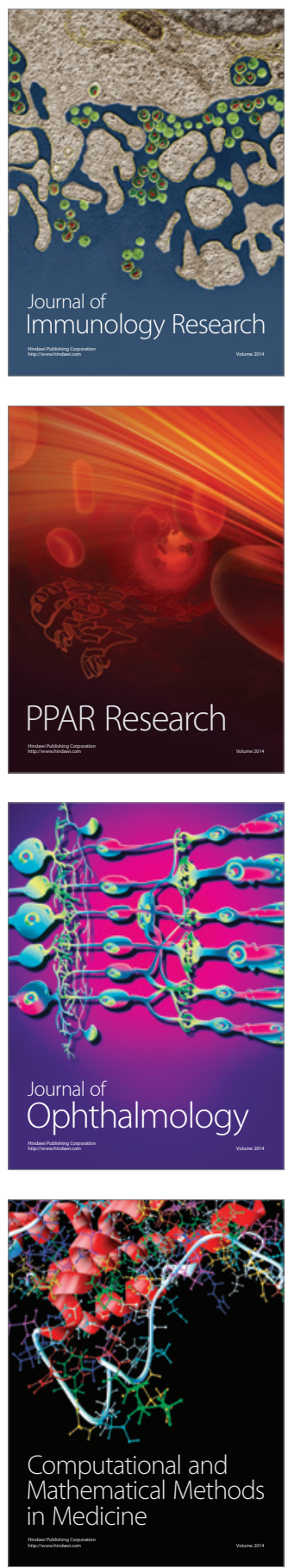

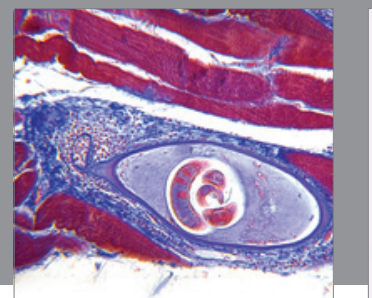

Gastroenterology

Research and Practice
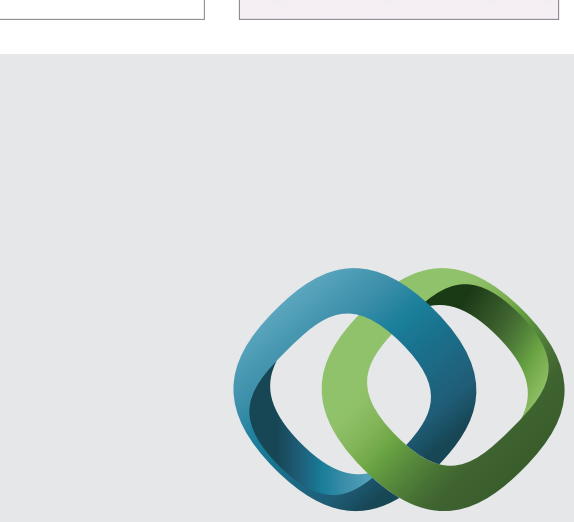

\section{Hindawi}

Submit your manuscripts at

http://www.hindawi.com
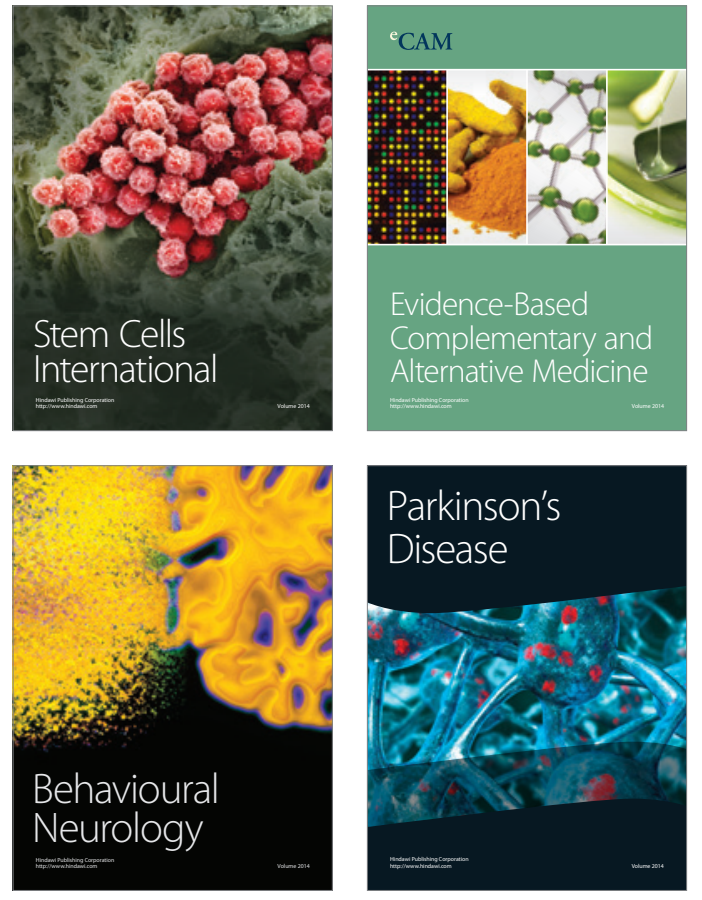
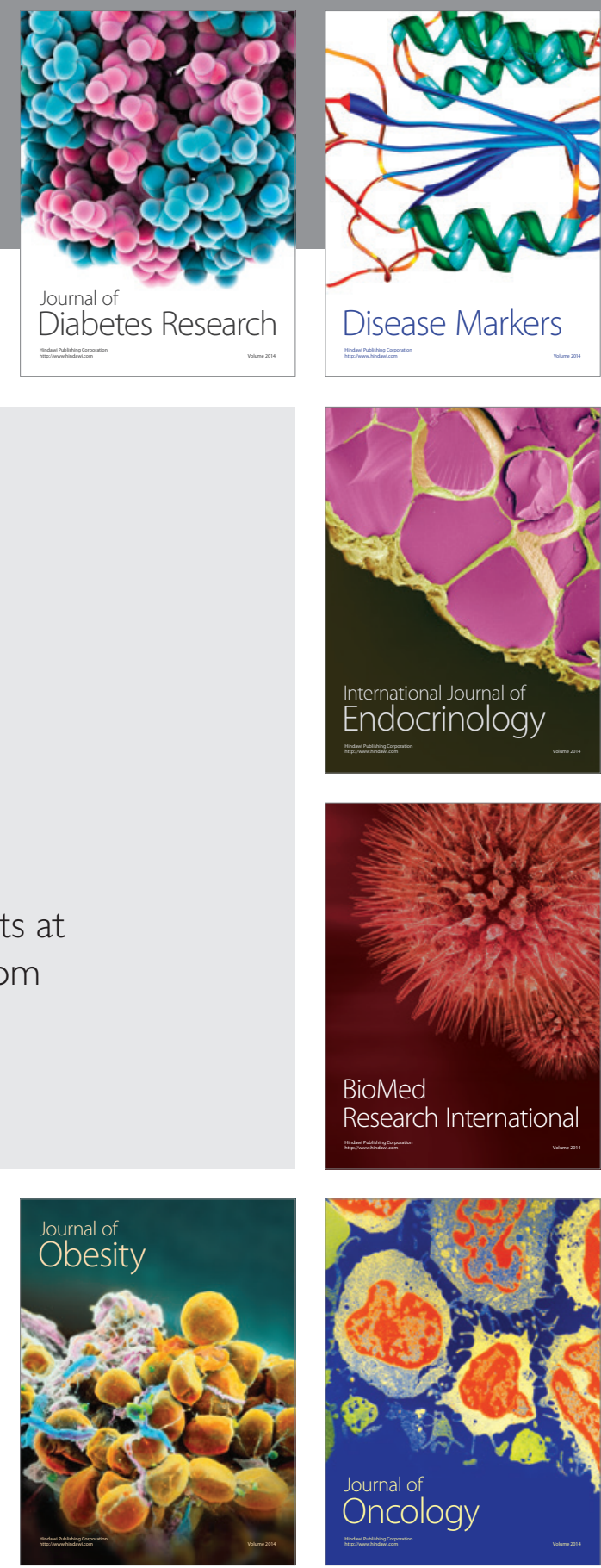

Disease Markers
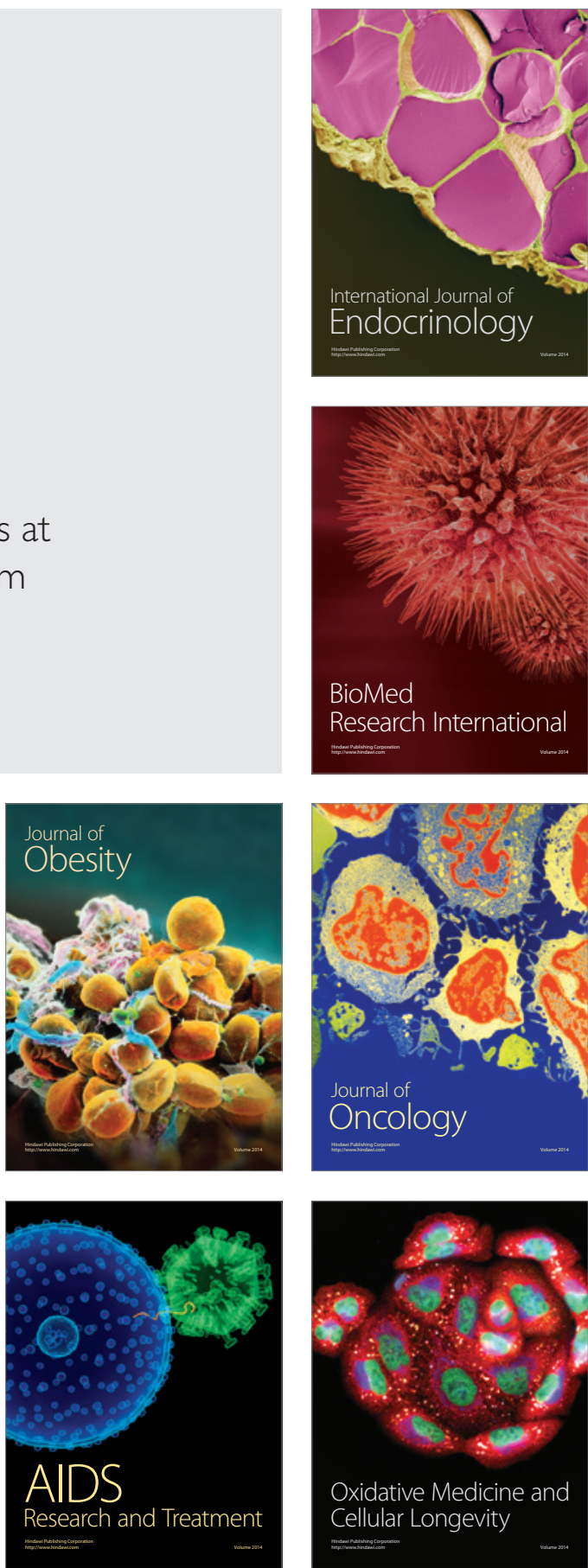